\title{
Study of the martensitic transformation in the Hafnium-Palladium system
}

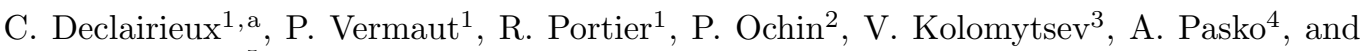 \\ G. Monastyrsky ${ }^{5}$ \\ 1 Chimie ParisTech, 11 rue Pierre et Marie Curie, 75231 Paris cedex 05, France \\ 2 Institut de Chimie et des Matériaux Paris-Est, CNRS, 2-8 rue Henri Dunant, 94320 Thiais, France \\ 3 Institute of Metal Physics of NASU, 36 Vernadsky av., 03142 Kyiv, Ukraine \\ 4 SATIE, École Normale Supérieure de Cachan, 61 av. du Président Wilson, 94235 Cachan, France \\ 5 National Technical University of Ukraine, 37 Peremogy av., 03058 Kyiv, Ukraine
}

\begin{abstract}
High temperature shape memory alloys have received a large interest for many years but none of the systems studied so far has led to industrial applications. Those alloys are expected to develop an actuating role in high temperature environment as for example aircraft turbines. Lots of criteria are required in order to substitute or optimize heavy existing actuators. Here are presented a few results obtained with the system hafnium-palladium, not so documented for the moment, that develops a martensitic transformation at around $773 \mathrm{~K}$. According to the characteristics of very well-known alloys such as $\mathrm{NiTi}$, some compositions around the equiatomic are explored. The main objective of our work is to know the influence of a stoechiometry gap on the microstructure of the alloys and the martensitic transformation.
\end{abstract}

\section{Introduction}

The shape memory alloys (SMA) developed and commercialised such as NiTi system undergo a martensitic transformation (MT) below $373 \mathrm{~K}$ but many fields of applications such as aeronautic or space require higher temperatures. In those domains, SMA can play an actuating role in engines of automobiles or in airjet turbines [1,2]. Several systems such as NiTi(Hf,Zr) [3,4], NiTiPd [5], Zr-Cu-based [3], ZrPd [6,7] or Ru-based [8] alloys have been studied during the recent years but none of them found any industrial application so far.

The hafnium-palladium system has received a very small attention in the past $[9,10]$ but could be a good candidate for high temperature applications. In this paper we present fundamental results about this system, focusing on the determination of the transformation temperatures and the martensite structure. We studied four different alloys around the equiatomic composition : $\mathrm{Hf}_{54} \mathrm{Pd}_{46}, \mathrm{Hf}_{52} \mathrm{Pd}_{48}, \mathrm{Hf}_{50} \mathrm{Pd}_{50}$ and $\mathrm{Hf}_{48} \mathrm{Pd}_{52}$ in order to know the influence of the composition on their properties.

\section{Experimental procedures}

Ingots of 20 grams have been elaborated from pure metals by arc melting under argon (700 mbar). Each ingot were remelted four times to ensure a good chemical homogeneity. The alloys

\footnotetext{
a e-mail: charles-declairieux@enscp.fr
} 
were annealed for 24 hours at $1373 \mathrm{~K}$ under a partial pressure of argon in a quartz crucible and water quenched.

Thermal analysis have been done by differential scanning calorimetry (DSC) with a MettlerToledo 822 e between room temperature (RT) and $973 \mathrm{~K}$ at a rate of $10 \mathrm{~K} / \mathrm{min}$. The phase composition was determined using a scanning electron microscope (SEM) Hitachi S2500 in backscattered electron (BSE) mode, energy-dispersive spectroscopy (EDS) using standards gave the quantitative analysis of individual phases.

Structural investigation has been carried out at room temperature using the Co K $\alpha$ radiation $(\lambda=1.789 \AA)$ for X-Ray diffraction (XRD), a Jeol 2000FX $(200 \mathrm{kV})$ for transmission electron microscopy (TEM).

\section{The martensitic transformation in $\mathbf{H f}_{50} \mathbf{P d}_{50}$}

\subsection{Transformation temperatures}

Figure 1 shows a DSC curve obtained with the equiatomic alloy. Unlike ZrPd [6,7], a unique MT is detected in HfPd between room temperature and $973 \mathrm{~K}$. The martensitic start temperature is $823 \mathrm{~K}$ and the austenite start temperature $927 \mathrm{~K}$.

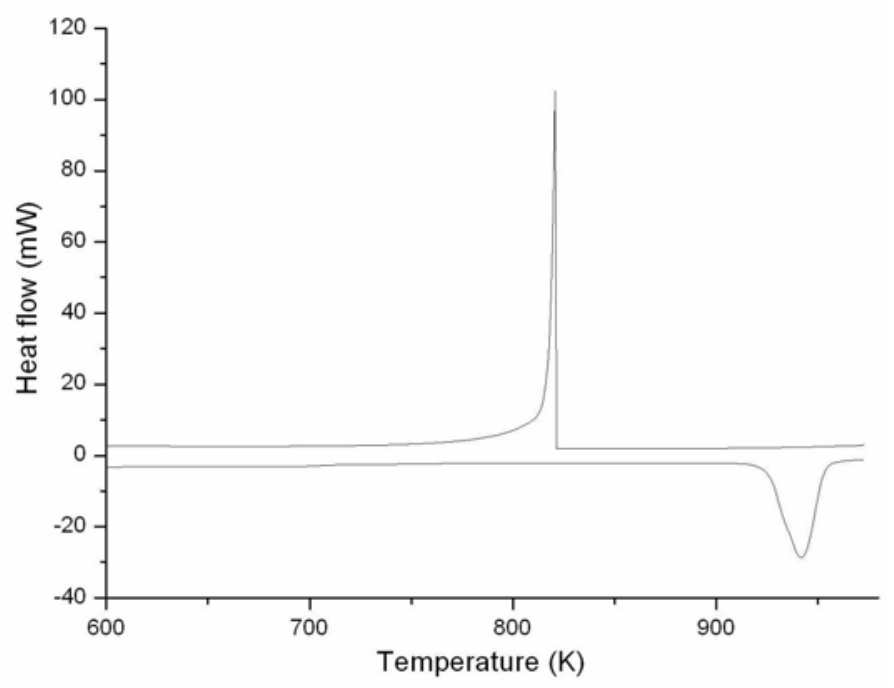

Fig. 1: DSC curve of $\mathrm{Hf}_{50} \mathrm{Pd}_{50}$ (exothermic up)

The shape of this DSC curve is relatively usual in this kind of alloys but we can notice that the martensitic transformation (exothermic) occurs very suddenly whereas the reversion is more progressive.

\subsection{Structural investigation}

On figure 2 are given a BSE image and XRD pattern of $\mathrm{Hf}_{50} \mathrm{Pd}_{50}$. We can see that this alloy is composed by two phases at room temperature (figure 2a). EDS measurements revealed that the white phase corresponds to $\mathrm{Hf}_{2} \mathrm{Pd}$ which is confirmed by some small peaks visible on the XRD spectrum (• on figure 2a, space group $I \frac{4}{m} m m$ with $a=3.25 \AA$ and $c=11.06 \AA$ ). This is in good agreement with the phase diagram of the Hf-Pd system presented by Tripathi et al. [10]. The dark phase has a composition very close to $\mathrm{Hf}_{50} \mathrm{Pd}_{50}$, this phase is the martensite of the HfPd system. 


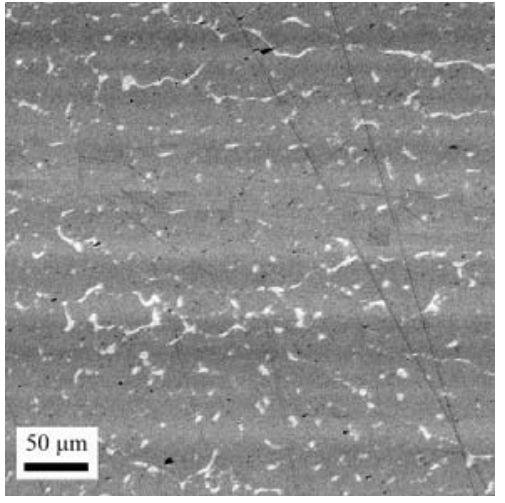

(a) BSE image of $\mathrm{Hf}_{50} \mathrm{Pd}_{50}$

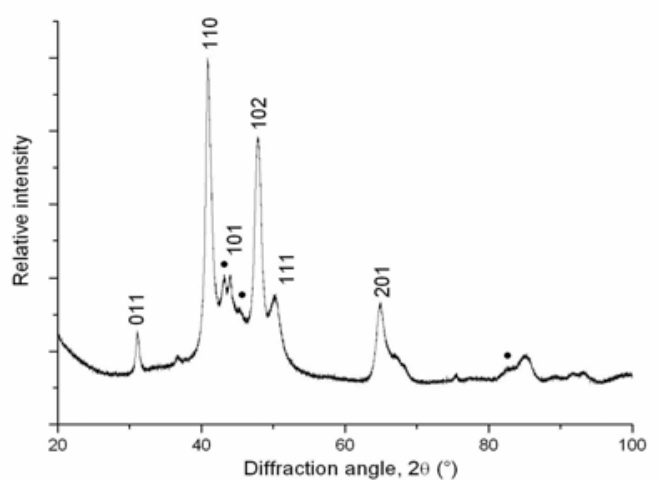

(b) XRD spectrum recorded at RT

Fig. 2: Phase composition of $\mathrm{Hf}_{50} \mathrm{Pd}_{50}$

It is well-known that the martensite of equiatomic NiTi presents a B19'-type structure belonging to the space group $P \frac{2_{1}}{m}$ [5]. Since Ti and Hf on one side and $\mathrm{Ni}$ and $\mathrm{Pd}$ on the other side belong to the same column in the periodic table of the elements, some similarities are expected between NiTi and HfPd compounds. The theoretical XRD pattern using this structure with modified lattice parameter in accordance with the bigger atomic radii of hafnium and palladium has been calculated. A good match has been obtained with the experimental pattern shown on figure $2 \mathrm{~b}$ with the following lattice parameters : $a=3.3 \AA, b=4.38 \AA$, $c=5.4 \AA$ and $\beta=108.2^{\circ}$.

TEM investigations and especially electron diffraction confirmed this good agreement since all the diffraction patterns recorded have been indexed with the structure detailed above.

As an example, figures $3 \mathrm{a}$ and $3 \mathrm{c}$ present two characteristic diffraction patterns of the martensite with electron beam parallel to [100] and [010] zone axis respectively, the latter showing the angle $\beta\left(\beta=\pi-\beta^{*}\right)$ of the monoclinic structure.

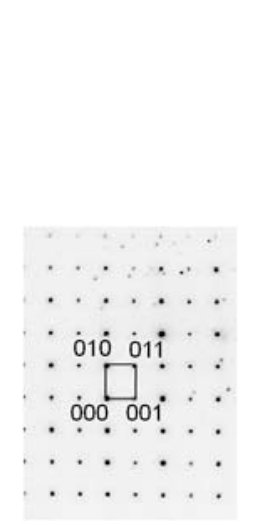

(a)

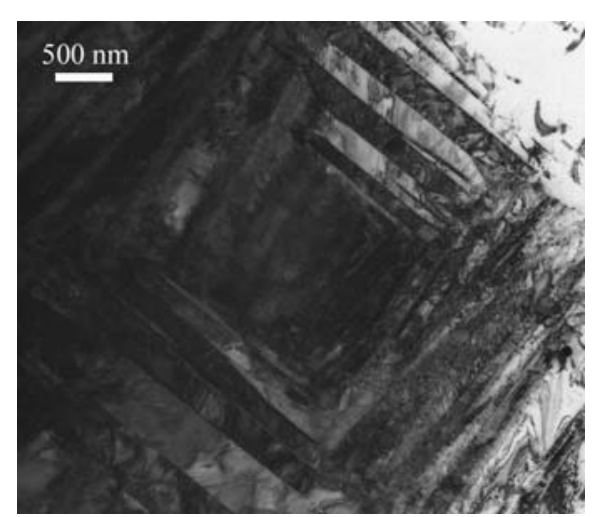

(b)

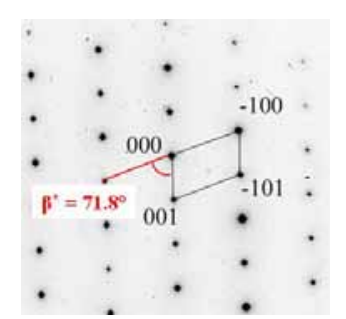

(c)

Fig. 3: Bright field image (b) and SAD patterns of $\mathrm{Hf}_{50} \mathrm{Pd}_{50}, \mathrm{~EB} / /[100]$ (a) and [010] (c)

The analysis of the martensite microstructure by TEM shows that numerous planar and line defects are still present even after the solution treatment. The width of martensite plates ranges from 100 to $500 \mathrm{~nm}$. Twinning interfaces are mainly planar excepted at the tip of the plates. Square-like self-accommodated groups have been observed as shown on figure 3b in addition to spear and fourch-like ones. 


\section{Influence of the stoechiometry}

Three other alloys were prepared, two with more hafnium $\left(\mathrm{Hf}_{54} \mathrm{Pd}_{46}\right.$ and $\left.\mathrm{Hf}_{52} \mathrm{Pd}_{48}\right)$ and one with more palladium $\left(\mathrm{Hf}_{48} \mathrm{Pd}_{52}\right)$, in order to investigate the influence of the chemical composition on the martensitic transformation.

\subsection{Effect on the transformation temperature}

The table 1 summarizes the characteritic temperatures (martensitic start $\mathrm{M}_{s}$ and finish $\mathrm{M}_{f}$, austenite start $\mathrm{A}_{s}$ and finish $\mathrm{A}_{f}$ temperatures) and the hysteresis measured by DSC. The graph presented on figure 4 shows the influence of the palladium content on the $\mathrm{M}_{s}$.

\begin{tabular}{cccccc}
\hline Composition & $\mathrm{M}_{s}$ & $\mathrm{M}_{f}$ & $\mathrm{~A}_{s}$ & $\mathrm{~A}_{f}$ & Hysteresis \\
\hline $\mathrm{Hf}_{54} \mathrm{Pd}_{46}$ & 813 & 798 & 905 & 930 & 130 \\
$\mathrm{Hf}_{52} \mathrm{Pd}_{48}$ & 826 & 793 & 930 & 943 & 120 \\
$\mathrm{Hf}_{50} \mathrm{Pd}_{50}$ & 821 & 793 & 927 & 953 & 120 \\
$\mathrm{Hf}_{48} \mathrm{Pd}_{52}$ & 756 & 731 & 923 & 953 & 130 \\
\hline
\end{tabular}

Table 1: Martensitic transformation temperatures and hysteresis of the studied alloys (K)

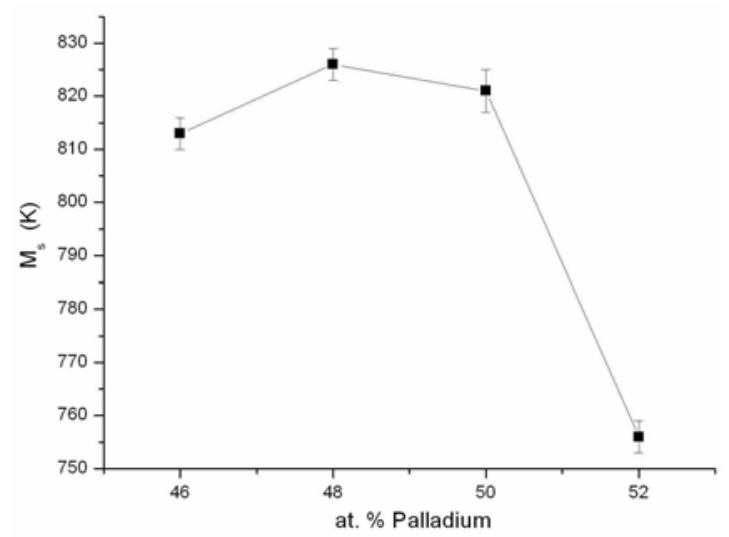

Fig. 4: $\mathrm{M}_{s}$ vs. Palladium content (at.\%)

We can point out the large difference between the behavior of the composition $\mathrm{Hf}_{48} \mathrm{Pd}_{52}$ and the three other compositions. In this alloy, the palladium excess makes the MT to occur at lower temperature, such as a nickel excess in NiTi. We also observed that the shape of the DSC curve of $\mathrm{Hf}_{48} \mathrm{Pd}_{52}$ for the MT was not as sharp as the others. The alloy composition seems to have no effect on the hysteresis which remain large.

\subsection{Effect on the microstructure}

The first observation which can be done on the BSE images figure 5 is that the composition $\mathrm{Hf}_{48} \mathrm{Pd}_{52}$ (d) looks single-phase whereas all the others present two different phases.

Such as $\mathrm{Hf}_{50} \mathrm{Pd}_{50}, \mathrm{Hf}_{54} \mathrm{Pd}_{46}$ and $\mathrm{Hf}_{52} \mathrm{Pd}_{48}$ present the phases $\mathrm{Hf}_{2} \mathrm{Pd}$ (white phase) and HfPd (dark phase) whereas in $\mathrm{Hf}_{48} \mathrm{Pd}_{52}$, a unique phase is detected. On pictures 5(a), (b) and (c) the volume fraction of $\mathrm{Hf}_{2} \mathrm{Pd}$ raises when the hafnium content increases. 


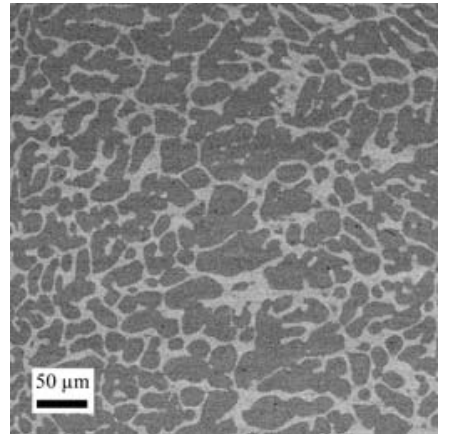

(a)

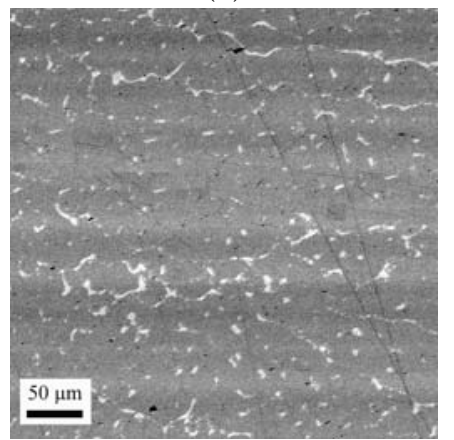

(d)

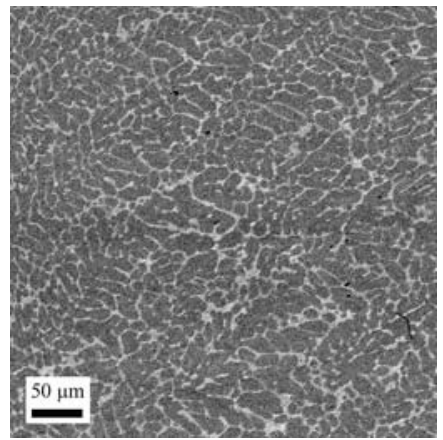

(b)

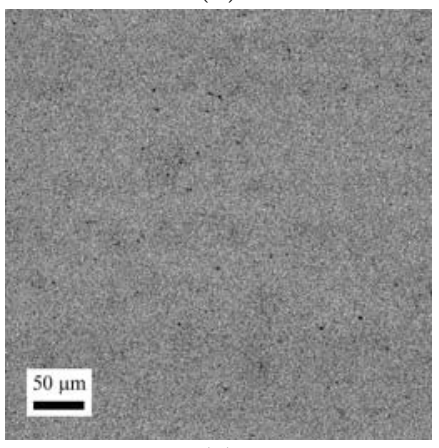

(c)

Fig. 5: BSE images of $\mathrm{Hf}_{54} \mathrm{Pd}_{46}(\mathrm{a}), \mathrm{Hf}_{52} \mathrm{Pd}_{48}$ (b), $\mathrm{Hf}_{50} \mathrm{Pd}_{50}$ (c) and $\mathrm{Hf}_{48} \mathrm{Pd}_{52}$ (d).

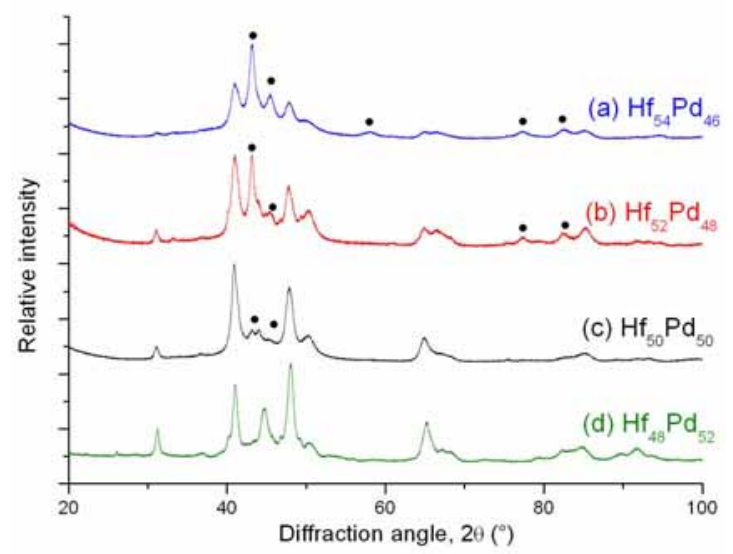

Fig. 6: XRD spectra recorded at RT, Co K $\alpha \lambda=1.789 \AA ; \bullet: \mathrm{Hf}_{2} \mathrm{Pd}$.

On figure 6 are given the XRD patterns obtained for the four compositions. Once again we can easily distinguish that the alloy $\mathrm{Hf}_{48} \mathrm{Pd}_{52}$ has a very particular behavior. The three other compositions present the same peaks with the relative proportion of the peaks corresponding to $\mathrm{Hf}_{2} \mathrm{Pd}$ growing with the hafnium content, which is consistent with SEM observations. The alloy containing a palladium excess only presents the peaks due to the martensite. According to those XRD patterns, where diffraction peaks are found for the same angles, we assume that the martensite is the same in the four alloys, with the structure detailled above.

From literature, the equiatomic range of the HfPd phase diagram is still unclear. According to Tripathi et al. [10], HfPd has a homogeneity range beginning at 50 at.\% $\mathrm{Pd}$ and extends beyond without a clear limit. Excess of Pd above this limit should lead to the formation of 
$\mathrm{Hf}_{3} \mathrm{Pd}_{4}$ compound by a peritectic reaction between $\mathrm{HfPd}$ and $\mathrm{HfPd}_{2}$. No information on the crystal structure of $\mathrm{Hf}_{3} \mathrm{Pd}_{4}$ is available up to now. From our results, since no $\mathrm{Hf}_{3} \mathrm{Pd}_{4}$ phase was detected, it seems that the limit of the homogeneity range of the HfPd compound is above 52 at.\% Pd. Further investigation by TEM is needed to clarify this point. However, this difference in the chemical composition of the martensite in the Pd-rich alloy can explain the decrease of the transformation temperatures.

\section{Conclusion}

The results presented in this paper give a basic knowledge about the Hf-Pd system close to the equiatomic composition. It has been demonstrated that these alloys undergo a martensitic transformation at high temperature. Such as the nickel in NiTi, palladium can be present in more than 50 at.\% in the martensite of HfPd and leads to a decrease of the MT temperatures. According to XRD and TEM experiments, a structure belonging to the space group $P \frac{2_{1}}{m}$ is proposed for the martensite, which is the same in the four compositions presented. TEM study of the twinning modes of the martensite and the microstructure of the Pd-rich alloy are under progress.

\section{Acknowledgment}

The authors thank the french national center of scientific research (CNRS) for its financial support in the PICS project $n^{\circ} 3747$ and Charles Declairieux also thanks the french fundation of research for aeronautics and space (FRAE) for its grant.

\section{References}

1. D. J. Hartl and D. C. Lagoudas, Proc. IMechE Special Issue Paper 221, (2007)

2. J. Van Humbeeck, Materials Science and Engineering A 273-275, (1999) 134-148

3. G. S. Firstov, J. Van Humbeeck and Y. N. Koval, Materials Science and Engineering A 378, (2004) $2-10$

4. F. Dalle, E. Perrin, P. Vermaut, M. Masse, R. Portier, Acta Materialia 50, (2002) 3557-3565

5. K. Otsuka and X. Ren, Intermetallics 7, (1999) 511-528

6. L. A. Bendersky, J. K. Stalick, R. Portier, R. M. Waterstrat, Journal of Alloys and Compounds 236, (1996) 19-25

7. T. Nishiura, T. Yamamuro, D. Hashimoto, Y. Morizono, M. Nishida, Materials Science and Engineering A 438-440, (2006) 852-856

8. K. Chastaing, Etude d'alliages à mémoire de forme base Ru pour applications hautes températures, PhD Thesis, Université Pierre et Marie Curie, 2007

9. V.N. Kuznetsov, G.P. Zhmurko and E.M. Sokolovskaya, Journal of the Less Common Metals 163, (1990) $1-8$

10. S. N. Tripathi and S. R. Bharadwaj, Journal of Phase Equilibria 16, (1995) 527-531 